\title{
JORNADAS DE JUNHO DE 2013: A CIDADE COMO PALCO DOS NOVOS MOVIMENTOS SOCIAIS DE PROTESTO BRASILEIROS
}

Mariana Pinto Zoccal ${ }^{1}$

ISSUE DOI: $10.21207 / 1983.4225 .356$

\section{RESUMO}

Neste artigo, pretende-se analisar o direito de manifestação à luz de nossa Constituição Federal, o panorama internacional em que se inserem os novos movimentos sociais de protesto brasileiros, o cenário de "inferno urbano" de nossas cidades e a falência de representatividade das atuais instituições políticas, com o objetivo de melhor compreender o fenômeno das Jornadas de junho de 2013 e os seus reflexos na arena política nacional.

Palavras-chave: Jornadas de Junho. Manifestações. Cidades. Inferno urbano.

\footnotetext{
${ }^{1}$ Acadêmica do $5^{\circ}$ ano de Direito na Faculdade de Direito de Franca; Bolsista de Iniciação Ciêntífica pelo PIBIC/CNPq durante o período 2014-2015; participou do IV Laboratório de Ciências Criminais do IBCCRIM - Ribeirão Preto.
} 


\section{ABSTRACT}

In this article, we intend to analyze the right of manifestation in light of our Federal Constitution, the international panorama in which the new movements of Brazilian social protest, the scenario of the "urban hell" of our cities and the bankruptcy of representativeness. The current political institutions, with the aim of better understanding the phenomenon of the Days of June 2013 and their reflections in the national political arena.

Keywords: June days. Manifestations. Cities. Inferential - not urban.

\section{INTRODUÇÃO}

O direito de reunião e manifestação encontra amparo em nossa Constituição Federal de 1988 e em diversos documentos internacionais como a Declaração Universal dos Direitos Humanos e o Pacto San José da Costa Rica. Entretanto, se analisarmos a conjuntura histórica das mobilizações de massa em nosso país, é possível observar que o exercício de tal direito quase sempre foi censurado quando se tornaram públicas pautas avessas aos interesses das classes hegemônicas.

Desde as mobilizações pelo impeachment do presidente Collor não havia mais registros da ocorrência de protestos com grande adesão popular no território brasileiro. Este hiato no exercício do direito de manifestação se deu em função de um afastamento da população, em especial dos jovens, da política e das instituições tradicionais de representação, como os partidos políticos.

Entretanto, a precariedade dos serviços públicos oferecidos pelo estado, somado a um contexto caótico de favelização, congestionamentos, degradação ambiental, violência urbana e profundas desigualdades sociais tornaram latente o sentimento de descontentamento para com a conjuntura posta e propiciaram a eclosão das jornadas de junho de 2013 e dos protestos que as sucederam. 
O direito de manifestação constitui faculdade assegurada a todos os brasileiros e estrangeiros residentes no País e provém de uma inter-relação das liberdades de reunião, expressão e associação. Tal direito é consagrado no art. $5^{\circ}$, inciso XVI de nossa Constituição Federal, que dispõe que "todos podem reunir-se pacificamente, sem armas, em locais abertos ao público, independentemente de autorização, desde que não frustrem outra reunião anteriormente convocada para o mesmo local, sendo apenas exigido o aviso à autoridade competente".

A liberdade de reunião e manifestação representa o exercício coletivo da liberdade de expressão. Ela objetiva combater o isolamento do particular e promover o desenvolvimento da personalidade do grupo. Ao manifestar-se contra o que está posto, o cidadão passa a influenciar de forma direta o processo político do país. Essa manifestação só adquire sentido a partir de uma perspectiva pluralista pautada na crítica e no dissenso.

Com efeito, não seria necessário consagrar aos cidadãos a liberdade de expressão para o fim de meramente confirmar os interesses da maioria. Uma tal sociedade ideal de consenso nem sequer se poderia considerar saudável ou materialmente democrática. [...] A liberdade de expressão assume, portanto, o sentido de conferir meios de participação social efetiva a todos, notadamente às minorias políticas, ainda que ostentem discursos antagônicos em relação aos valores dominantes ou aos pretensos interesses do Estado, pois no jogo democrático o poder político há de se submeter à razão, e não o contrário. ${ }^{2}$

A intervenção policial deve orientar-se a fim de prevenir o perigo de perturbação da ordem e isolar os perturbadores que estejam prejudicando a manifestação. Apenas em ultima ratio policiais poderão dissolver reuniões e atuar contra manifestantes pacíficos. As autoridades devem primar pelo diálogo, pela informação e pelo aconselhamento dos promotores do evento.

2 BECHARA, Ana Elisa Liberatore Silva. Liberdade de expressão e manifestações populares no âmbito democrático. Boletim IBCCrim. Ano 21, n. 249, agosto/2013. p. 16. 
[...] uma determinação do Poder Público no sentido de proibir ou suspender a reunião, inclusive mediante o uso da força policial, deverá sempre ter caráter excepcional e apenas se justifica quando os atos praticados durante a reunião afetem direitos fundamentais de terceiros de modo significativo ou coloquem em risco a ordem pública, sem que, contudo, se interprete a noção de ordem pública de modo genérico. Apenas a clara indicação de que a reunião está afetando concretamente a segurança pública poderá justificar as restrições mais gravosas do direito de reunião, como é o caso da proibição e da dissolução. ${ }^{3}$

O nosso ordenamento jurídico apresenta uma preocupante lacuna na tutela do direito de manifestação, visto que inexiste legislação específica que regulamente o uso da força policial em manifestações. Dessa forma, o Estado adquire margem discricionária para que ele utilize o seu poder de coação de forma desproporcional e arbitrária. Urge, portanto, que ocorra a regulamentação da atividade policial conforme o padrão adotado por documentos internacionais de direitos humanos, para sanar o quadro de insegurança jurídica a que estamos submetidos em ocorrências durante os protestos.

\section{PANORAMA INTERNACIONAL DOS NOVOS MOVIMENTOS SOCIAIS DE PROTESTO}

Desde 2010, uma onda revolucionária de protestos e manifestações espalhou-se pelo mundo. Tudo começou na Tunísia, em uma pequena cidade chamada Sidi Bouzid, na região central do país. Lá, o vendedor ambulante Mohamed Bouazizi, após ter sua banca de frutas confiscada devido ao não pagamento de propina à polícia local, rebelou-se contra a violência da ditadura em que vivia e promoveu a sua autoimolação por fogo diante a um prédio do governo como forma de protesto. $\mathrm{O}$ ato foi filmado e o vídeo espalhou-se pela internet, tornando-se um combustível para que a juventude do país se rebelasse contra o regime posto. O movimento conseguiu

${ }^{3}$ SARLET, Ingo Wolfgang; MARINONI, Luiz Guilherme; MITIDIERO, Daniel. Curso de Direito Constituional. 3. ed. São Paulo: Editora Revista dos Tribunais Ltda, 2014. p. 534. 
derrubar a truculenta ditadura de Ben Ali e influenciou outros diversos países do mundo árabe como o Egito, a Líbia e o Iêmen a protestarem por democracia.

A partir do episódio supracitado, as manifestações estenderamse pela Europa. Na Espanha, o Movimento dos Indignados, também conhecido por 15M, referência a sua data de início - 15 de maio de 2011, ocupou praças públicas para protestar por uma democracia real. Ele foi considerado a principal resposta da população frente à crise espanhola. Seus membros "protestavam contra o desmonte do Estado de bem-estar social, a política de austeridade do governo com cortes nos salários, aposentadorias, fechamento de escolas, cobrança nos tratamentos de saúde etc". 4

Nos Estados Unidos, o movimento "Occupy Wall Street” trouxe à tona uma crítica radical ao capitalismo como modo de produção da vida social, refletida em slogans como "Injustiças perpetradas por $1 \%$ da população - elites políticas e econômicas afetam os outros 99\%, nós". O movimento teve por pautas "o repúdio ao desemprego, a desigualdade social, a insaciável busca de lucros pelas corporações financeiras, a corrupção, a condenação de lobistas que defendem interesses privados junto ao poder público etc". 5

Na América Latina, movimentos como a reivindicação estudantil por uma educação pública e gratuita no Chile e os protestos de junho de 2013 também foram expressões dos novos movimentos sociais de protesto que tomaram as ruas de todo o mundo.

De acordo com Carneiro ${ }^{6}$, o pano de fundo objetivo de todos esses protestos é uma crise social, econômica e financeira que se arrasta desde 2008 e promove a carestia dos gêneros alimentares e o aumento do desemprego. Para ele, em todos os países houve uma mesma forma de ação: a ocupação de praças, o uso de redes de comunicação alternativas e as articulações políticas que recusavam o espaço institucional tradicional.

Telefones celulares e redes sociais da internet como o Twitter e o Facebook foram essenciais para a divulgação de imagens e mensagens de mobilização e constituíram uma "plataforma de discussão, convocando

\footnotetext{
${ }^{4}$ GOHN, Maria da Glória. Manifestações de junho de 2013 no Brasil e praças dos indignados no mundo. Petrópolis, RJ: Editora Vozes, 2014. p. 110.

${ }^{5}$ Ibidem. p. 126.

${ }^{6}$ CARNEIRO, Henrique Soares. Rebeliões e ocupações de 2011. In: HARVEY, David et al. Tradução de João Alexandre Peschanski. Occupy: movimentos de protesto que tomaram as ruas. São Paulo: Boitempo Editorial: Carta Maior, 2012. p. 25.
} 
à ação, coordenando e organizando os protestos e abastecendo a população em geral de informações e debates". 7

Os movimentos espalharam-se por contágio num mundo ligado pela internet sem fio e caracterizado pela difusão rápida, viral, de imagens e ideias. Começaram no sul e no norte da Tunísia e na Islândia, e de lá a centelha acendeu o fogo numa paisagem social diversificada e devastada pela ambição e manipulação em todos os recantos deste planeta azul. Não foram apenas a pobreza, a crise econômica ou a falta de democracia que causaram essa rebelião multifacetada. Evidentemente, todas essas dolorosas manifestações de uma sociedade injusta e de uma comunidade política não democrática estavam presentes nos protestos. Mas foi basicamente a humilhação provocada pelo cinismo e pela arrogância das pessoas no poder, seja ele financeiro, político ou cultural, que uniu aqueles que transformaram medo em indignação, e indignação em esperança de uma humanidade melhor. ${ }^{8}$

\section{O “INFERNO URBANO” E A FALÊNCIA DE REPRESENTATIVIDADE DAS INSTITUIÇÕES POLÍTICAS BRASILEIRAS}

Chauí entende por "inferno urbano" os traços marcantes que caracterizam a situação da vida urbana nas grandes metrópoles brasileiras. Entre eles, destacam-se: a explosão do uso do automóvel individual em detrimento do transporte coletivo, a verticalização dos condomínios e

\footnotetext{
${ }^{7}$ CASTELLS, Manuel. Redes de indignação e esperança: movimentos sociais na era da internet. Tradução de Carlos Alberto Medeiros. Rio de Janeiro: Jorge Zahar Editor, 2012.p. 48.

${ }^{8}$ Ibidem. p. 12.
} 
shopping centers e a expulsão dos moradores de áreas favorecidas pela especulação imobiliária para bairros periféricos, distantes dos locais de trabalho e carentes de educação e serviços de saúde. ${ }^{9}$

Segundo a autora, tal conjuntura serve de base concreta para a crítica às instituições políticas, que adquire fundamento se considerarmos que a qualidade dos Poderes Legislativos nos três níveis é baixa. Frequentemente escândalos de corrupção ganham publicidade e expõem as relações de favor, clientela, tutela e cooptação que pautam a atuação dos partidos políticos, cada vez mais interessados em utilizar o público para a obtenção de benefícios privados.

Uma análise do período posterior à ascensão do Partido dos Trabalhadores (PT) ao governo mostra que o partido reproduziu em sua gestão uma política de coalizão incongruente com o campo das lutas sociais autoorganizadas, transformando-se em uma máquina burocrática e eleitoral. Ricci afirma que o governo PT interditou os canais sociais por onde as demandas das ruas eram organizadas e transformadas em pautas. Organizações não governamentais (ONGs), pastorais sindicais, sindicatos, entidades de representação e mobilização social passaram a ingressar a estrutura de Estado ou a terceirizar serviços públicos por meio de convênios, dificultando o acolhimento das insatisfações populares. ${ }^{10}$

A política governamental utilizada para enfrentar a crise econômica mundial de 2009 consistiu em oferecer incentivos às indústrias automobilísticas a fim de facilitar a compra de automóveis individuais, mas em contrapartida intensificou problemas como os congestionamentos, os acidentes de trânsito e a poluição do ar atmosférico. Ademais, os investimentos em transporte coletivo foram mínimos. Para Bicalho, "o sonho de modernidade do século XX se transformou no pesadelo da imobilidade e, mesmo para a minoria que tem acesso aos automóveis, este modelo dá sinais claros de esgotamento".

${ }^{9}$ CHAUÍ, Marilena. As manifestações de junho de 2013 na cidade de São Paulo. Teoria e Debate, 27 jun. 2013. Disponível em: <http://www.teoriaedebate.org.br/materias/nacional/manifestacoes-de-junho-de-2013-na-cidade-de-sao-paulo>. Acesso: 26 jun. 2015.

${ }^{10}$ RICCI, Rudá. A disputa política está nas ruas. In: ALVES, Giovanni; ROCHA, Bruno Lima; GADEA, Carlos; COCCO, Giuseppe, VIANNA, Luiz Werneck; RICCI, Rudá. \#VEMpraRUA: outono brasileiro? Leituras. Caderno IHU Ideias, 2013, ano 11, nº191, p. 28. Disponível em: <http://www.ihu.unisinos.br/images/stories/cadernos/ideias/191xcadernosihuideias.pdf >. Acesso: 26 jun. 2015. p. 28. 
O déficit de democracia participativa e o crescente descontentamento relacionado aos serviços públicos precários oferecidos pelo Estado, aliado à influência das intensas mobilizações populares em diversas partes do mundo fizeram florescer na população brasileira um sentimento de indignação para com a conjuntura posta. Maior preceitua que:

uma das maiores injustiças que se pode cometer é a de impedir que as vítimas da injustiça social e da intolerância tenham voz, mantendo-as órfãs de uma ação política institucional efetivamente voltada ao atendimento de suas necessidades. ${ }^{11}$

Destarte, órfã de canais institucionais que possibilitem a expressão de suas reivindicações e carente de um Estado social que ofereça de fato serviços públicos nas áreas da saúde, educação, segurança e transporte com qualidade, a população brasileira encontrou nas manifestações de junho de 2013 uma oportunidade de romper com o silêncio e a apatia então instaurados e levar suas demandas de forma direta a seus governantes.

\section{AS JORNADAS DE JUNHO DE 2013 E OS SEUS REFLEXOS NA ARENA POLÍTICA NACIONAL}

O estopim para a eclosão das Jornadas de Junho foi o aumento de 20 centavos no valor da tarifa de ônibus da capital paulista. Liderada pelo Movimento Passe Livre (MPL), a primeira mobilização teve início no dia 6 junho e contou com a participação de aproximadamente dois mil manifestantes.

O MPL foi fundado no ano de 2005, no V Fórum Social Mundial em Porto Alegre. Ele caracteriza-se por ser um movimento social de transportes autônomo, apartidário e horizontal, cujos coletivos locais, federados, não se submetem a qualquer organização central. Sua principal luta pauta-se na gratuidade do transporte público, pois defende que o transporte

\footnotetext{
${ }^{11}$ MAIOR, Jorge Luiz Souto. A vez do direito social e da descriminalização dos movimentos sociais. In: MARICATO, Hermínia et al. Cidades rebeldes: Passe Livre e as manifestações que tomaram as ruas do Brasil. São Paulo: Boitempo Editorial: Carta Maior, 2013. p. 88 .
} 
é um direito fundamental para a efetivação de outros direitos, à medida que garante o acesso a serviços públicos como saúde, educação, cultura e lazer.

O MPL coloca na mesa da discussão política a proposta da tarifa zero, do transporte público gratuito. Trata-se de uma proposta ambiciosa que, se aplicada, tem repercussões fundamentais no modo como organizamos nossa sociedade. E, mais do que isso, é realista. Há um caráter utópico inegável no passe livre: a ideia de que, nas cidades, vamos priorizar a justiça econômica de um transporte acessível a todos - intensificada se a sustentação do sistema de transporte for feita com base em um imposto progressivo - e o equilíbrio ambiental, em detrimento de um modelo empresarial de gestão e prestação desse serviço (no caso dos transportes, pelo menos em São Paulo, com características mafiosas). Há um componente realista, na medida em que, na ponta do lápis, é uma proposta não apenas desejável, mas até mais eficiente e racional de organizar o transporte urbano. $^{12}$

Os atos de protesto que ocorreram nos dias 8 e 11 de junho tiveram uma maior adesão populacional, principalmente de estudantes. Cerca de 5.000 mil pessoas reuniram-se na capital paulista para protestar contra o aumento da tarifa. No $3^{\circ}$ ato, houve violência, " 19 pessoas foram detidas, inclusive jornalistas, cerca de 100 pessoas foram feridas (manifestantes, jornalistas e policiais), 87 ônibus foram queimados ou apedrejados, vitrines quebradas, bancos depredados e estações de metrô danificadas". ${ }^{13}$

$\mathrm{O} 4^{\circ}$ ato de protesto contra a tarifa caracterizou-se por uma inversão na abordagem dada pela mídia ao fenômeno das manifestações. Realizado no dia 13 de junho, o ato contou com a participação de 20 mil participantes segundo o MPL, e 5.000 conforme a Polícia Militar. A atuação

12 PESCHANSKI, João Alexandre. Direita e esquerda no espectro do pacto do silêncio.
Publicação oficial da Associação dos Juízes para a democracia. Ano 14, n. 60, agosto/2013,
p. 05.
${ }^{13}$ GOHN, Maria da Glória. Manifestações de junho de 2013 no Brasil e praças dos indignados no mundo. Petrópolis, RJ: Editora Vozes, 2014. p. 26-27. 
truculenta da polícia durante o evento deixou um saldo de aproximadamente duzentas detenções e provocou uma virada na opinião pública acerca dos protestos.

Até então o tratamento que os manifestantes recebiam na mídia resume-se a um termo/denominador: vândalos. A violência policial contra os manifestantes, que já havia acontecido no ato anterior, nesse $4^{\circ}$ ato foi de tal ordem que provocou repulsa e revolta na população. A polícia tratou a todos como inimigos, houve centenas de feridos, muitas prisões e muita indignação. ${ }^{14}$

Ainda no dia 13 de junho, o prefeito de São Paulo, Fernando Haddad posicionou-se contrário aos excessos do uso da força policial na repressão aos protestos, mas manteve a sua posição a respeito do aumento no preço da tarifa de transporte. O movimento se fortaleceu e eventos semelhantes espalharam-se pelo país, alguns em solidariedade aos manifestantes paulistanos que tinham sido presos e sofrido agressões, outros reivindicando a reforma política e social do Brasil.

Uma pesquisa feita pelo instituto Datafolha ${ }^{15}$ no dia 18 de junho mostrou que o apoio da população paulistana ao movimento subiu de 55\% para $77 \%$. A dimensão do fenômeno expandiu-se de tal forma que brasileiros foram às ruas em mais de 120 cidades, totalizando aproximadamente 1,5 milhões de pessoas. A intensa pressão popular, somada à decisão de prefeituras de cidades como o Rio de Janeiro, Recife, Cuiabá, Porto Alegre e João Pessoa de eliminar o aumento da tarifa, fizeram com que o prefeito Fernando Haddad retrocedesse em seu primeiro posicionamento e mantivesse a tarifa no valor de $\mathrm{R} \$ 3,00$.

Embora a principal pauta das manifestações tenha sido alcançada com a redução das tarifas, os atos de protesto continuaram ocorrendo nas capitais e principais cidades do interior do país. Nota-se que, a partir de

${ }^{14}$ GOHN, Maria da Glória. Manifestações de junho de 2013 no Brasil e praças dos indignados no mundo. Petrópolis, RJ: Editora Vozes, 2014. p. 26-27.

${ }^{15}$ DATAFOLHA. Cresce apoio a protestos contra a tarifas de ônibus entre paulistanos.

Disponível em: <http://datafolha.folha.uol.com.br/opiniaopublica/2013/06/1297619cresce-apoio-a-protestos-contra-a-tarifa-de-onibus-entre-paulistanos.shtml>. Acesso: 23 ago. 2014. 
então, as bandeiras levantadas pelos manifestantes modificaram-se. O movimento que a princípio possuía caráter apartidário e centrava suas demandas na seara dos transportes, adquiriu um viés anti-partidário e aderiu pautas difusas, por vezes contraditórias, como a indignação relacionada à corrupção, à alta carga tributária, ao descontentamento para com os serviços públicos prestados pelo Estado, aos gastos exorbitantes em obras para sediar eventos como a Copa do Mundo de Futebol de 2014 e as Olimpíadas de 2016 e à Proposta de Emenda Constitucional 37 (PEC 37) que objetivava retirar o poder investigativo do Ministério Público.

A incorporação de novas bandeiras às manifestações foi fruto de uma estratégia da grande mídia, que a partir do momento em que observou o fortalecimento do movimento, utilizou todo o seu aparato de comunicação para influenciar no direcionamento que era conveniente dar às massas. A partir de então, o movimento que claramente possuía um viés progressista passou a agregar manifestantes que defendiam pautas conservadoras como a redução a maioridade penal e o repúdio a descriminalização do aborto.

Inicialmente, os grandes veículos de comunicação deram às manifestações sua cobertura habitual: enfoque nos transtornos para as cidades, especialmente o trânsito, e nos confrontos com a polícia. Após a forte repressão a manifestantes em São Paulo, no dia 13 de junho, e a reação indignada da população, o tom da cobertura mudou. A mídia corporativa assumiu seu papel de centralizador das forças conservadoras, passou a ressaltar o caráter pacífico dos atos e a disputar a pauta do movimento. Reivindicações normalmente encampadas pela direita começaram a surgir nas manifestações. Até mesmo pequenos grupos de extrema direita marcaram presença em atos na cidade e provocaram e agrediram militantes de esquerda. ${ }^{16}$

\footnotetext{
16 BRASILINO, Luís; GODOY, Renato; NAVARRO, Cristiano. O junho de 2013. Le monde diplomatique Brasil. 02 jul. 2013. Disponível em: <http://www.diplomatique.org.br/artigo.php?id=1447>. Acesso: 07 jan. 2015.
} 
No dia 21 de junho, o MPL fez um anúncio informando que não convocaria mais atos de protesto $^{17}$, visto que a sua principal pauta havia sido alcançada e expressou o seu repúdio à hostilidade contra os militantes de partidos políticos ocorrida nos últimos eventos. A mobilização que nasceu com um caráter apartidário transformou-se em um movimento despolitizado, de indignação generalizada contra o Estado e seus representantes. "Assim, em lugar de inventar uma nova política, de ir rumo a uma invenção democrática, o pensamento mágico de grande parte dos manifestantes se ergueu contra a política, reduzida à figura da corrupção.” (CHAUÍ, 2013)

As Jornadas de Junho de 2013 tiveram sua legitimidade declarada pela presidente Dilma Rousseff, que comprometeu-se a "ouvir as vozes das ruas" 18 e promover melhorias nos setores da educação, saúde e mobilidade urbana, além trazer o debate acerca da necessidade de implementação de uma reforma política no país. O Congresso Nacional também mobilizouse de forma emergencial para votar e arquivar projetos, numa tentativa de sinalizar ao povo que suas demandas estavam sendo acolhidas.

[...] o Congresso Nacional, com propósito de igualmente dar uma resposta às "vozes das ruas", deu início a votação de pautas da "agenda positiva": apreciação de projetos de lei com o objetivo de atender parte das reivindicações pleiteadas pelos manifestantes. Em dois dias, como resultado da "agenda positiva", houve aprovação pelo Senado das seguintes pautas: a) a tipificação da corrupção como crime hediondo (PLS 204/2011); b) a inclusão do transporte público como parte dos direitos sociais (PEC 90/2011), c) a redução das exigências para apresentação de Projetos de Iniciativa Popular (PEC 03/2011 e PEC 45/2011) e d) a permanência de atribuição ao Ministério Público em conduzir

\footnotetext{
${ }^{17}$ ESTADÃO. MPL anuncia que não convocará mais protestos em SP. Disponível em: $<$ http://www.estadao.com.br/noticias/geral,mpl-anuncia-que-nao-convocara-mais-protestos-em-sp,1045263>. Acesso: 23 jun. 2015.

18 Planalto Nacional. Pronunciamento da presidente da república, Dilma Rousseff, em cadeia nacional de rádio e TV. Secretaria de Comunicação Social da Presidência da República: Discursos. Brasília, de 21 de junho de 2013.
} 
investigações criminais e a consequente recusa das diretrizes propostas pela PEC-37. ${ }^{19}$

É uma tarefa difícil caracterizar o perfil dos participantes de uma manifestação de massa, visto que crianças, jovens, adultos e idosos de diversos graus de escolaridade e poder aquisitivo fizeram-se presentes no movimento. Uma pesquisa do Ibope ${ }^{20}$ indicou que a idade predominante foi de 14 a 24 anos (43\%). 63\% dos participantes possuíam de 14 a 29 anos. O grau de escolaridade revela que a $43 \%$ possuíam curso superior e $49 \%$ ensino básico completo e superior incompleto. No tocante à renda familiar, $49 \%$ dos manifestantes sobreviviam com uma renda superior a cinco salários mínimos.

Alves (2013, p. 35) caracteriza os manifestantes como representantes do precariado. Conforme a sua definição, "o precariado é a camada média do subproletariado urbano, constituída por jovens-adultos altamente escolarizados, mas com inserção precária nas relações de trabalho e vida social". 21

[...] os jovens não vivenciam apenas uma "precarização salarial" por conta do desemprego, dos baixos salários e dos contratos salariais precários, mas estão diante de uma "precarização existencial que ocorre com a precariedade dos serviços públicos nas cidades brasileiras - transporte público, saúde,

\footnotetext{
${ }^{19}$ PUJOL, Antoni Francesc Tulla i; ROCHA, Fernando Goulart; SAMPAIO, Fernando dos Santos. Manifestações populares no Brasil atual: sociedade civil em rede e reivindicações sobre o poder político. In: XIII COLOQUIO INTERNACIONAL DE GEOCRÍTICA: El control del espacio y los espacios del control. Barcelona, 05-10 mai, 2014, p. 9. Disponível em: $<$ http://www.ub.edu/geocrit/coloquio2014/Antoni\%20Francesc\%20Tulla\%20i\%20Pujol.pdf>. Acesso: 20 jan. 2015. p. 9.

${ }^{20}$ G1. Veja pesquisa completa do Ibope sobre os manifestantes. Disponível em: <http://g1.globo.com/brasil/noticia/2013/06/veja-integra-da-pesquisa-do-ibope-sobre-osmanifestantes.html >. Acesso: 26 jun. 2015.

${ }^{21}$ ALVES, Giovanni. Precariado: a espinha dorsal dos protestos nas ruas das 353 cidades brasileiras. In: ALVES, Giovanni; ROCHA, Bruno Lima; GADEA, Carlos; COCCO, Giuseppe, VIANNA, Luiz Werneck; RICCI, Rudá. \#VEMpraRUA: outono brasileiro? Leituras. Caderno IHU Ideias, 2013, ano 11, nº191, p. 34-35. Disponível em: <http://www.ihu.unisinos.br/images/stories/cadernos/ideias/191xcadernosihuideias.pdf>. Acesso: 26 jun. 2015. p. 35.
} 
educação, espaços públicos - e o modo de vida justin-time". ${ }^{22}$

Durante as Jornadas de Junho e principalmente nos meses que as sucederam, a participação de coletivos como o Black Bloc nos atos de protesto foi destaque nas principais mídias do país e dividiu a opinião pública em favoráveis e contrários a sua tática de ação direta. Considerado um movimento de ideologia anarquista, o Black Bloc surgiu na Alemanha no início dos anos de 1980. Posteriormente o seu modo de agir foi reproduzido por adeptos do Movimento Anarcopunk.

A tática de ação direta consiste em romper com o pacifismo presente nas manifestações e realizar ataques seletivos contra símbolos do capitalismo global com o objetivo de chamar a atenção para suas demandas. Suas ações são performáticas e realizadas no anonimato, graças à utilização de máscaras e roupas pretas. Os membros do movimento argumentam que "a depredação não é violência, mas é uma intervenção simbólica que atinge o cerne do capitalismo: a propriedade privada. Violência, para esses manifestantes, é ferir pessoas, e isso é o que a polícia faz". ${ }^{23}$

As opiniões acerca dos Black Blocs são muitas vezes contraditórias. Delmanto tece as seguintes considerações sobre os adeptos do coletivo:

Aproveitando-se de protestos pacíficos, durante ou ao final deles, passam a praticar depredações do patrimônio público e privado, saquear, provocar incêndios e atirar coquetéis molotov, por vezes até com o auxílio de grandes estilingues. Armados de bastões e porretes, encobrem o rosto com lenços ou capuzes para não serem identificados, e alguns usam

\footnotetext{
${ }^{22}$ ALVES, Giovanni. Precariado: a espinha dorsal dos protestos nas ruas das 353 cidades brasileiras. In: ALVES, Giovanni; ROCHA, Bruno Lima; GADEA, Carlos; COCCO, Giuseppe, VIANNA, Luiz Werneck; RICCI, Rudá. \#VEMpraRUA: outono brasileiro? Leituras. Caderno IHU Ideias, 2013, ano 11, nº191, p. 34-35. Disponível em: <http://www.ihu.unisinos.br/images/stories/cadernos/ideias/191xcadernosihuideias.pdf>. Acesso: 26 jun. 2015. p. 35.

${ }^{23}$ GOHN, Maria da Glória. Manifestações de junho de 2013 no Brasil e praças dos indignados no mundo. Petrópolis, RJ: Editora Vozes, 2014. p. 58.
} 
até máscaras antigases. São contra tudo e todos, e principalmente contra a ordem constituída. ${ }^{24}$

Ortellado, por sua vez, rompe com o senso comum e reconhece a mensagem política transmitida por trás de cada ação direta do grupo. Seu posicionamento permite-nos questionar quais são os reais bens jurídicos relevantes para o Estado, visto que a proteção da vida humana é muitas vezes negligenciada se comparado à tutela oferecida a bens patrimoniais.

Enquanto a destruição da vidraça de bancos ganha enorme visibilidade, a repressão da polícia a manifestantes pacíficos segue invisível para a maior parte da grande imprensa. E não é só a agressão a manifestantes que é invisível. Toda a ação abusiva e violenta da polícia nas periferias das grandes cidades não recebe cobertura ou recebe uma cobertura discreta, sem destaque editorial. ${ }^{25}$

A utilização de táticas como a ação direta foram duramente rechaçadas pela mídia e pela maioria da população, contribuindo para que, novamente, as mobilizações fossem deslegitimadas. Protestos voltaram a ocorrer durante a Copa do Mundo de Futebol em 2014, mediante o anúncio de um novo aumento no valor das tarifas de transporte público no início de 2015, mas obtiveram menor adesão popular que a alcançada pelas Jornadas de Junho.

A eleição presidencial ocorrida no dia 26 de outubro de 2014, que culminou na vitória da presidente Dilma Rousseff, teve a votação mais acirrada desde 1989. Dilma obteve $51,64 \%$ dos votos e o senador Aécio Neves, 48,36\%. O reflexo dessa disputa que dividiu o Brasil foi a intensificação de um sentimento de frustração experimentado por uma grande parcela da população.

A reforma da Previdência, os escândalos de corrupção revelados pela operação Lava Jato, somados a uma série de ajustes que encareceram

${ }^{24}$ GOHN, Maria da Glória. Manifestações de junho de 2013 no Brasil e praças dos indignados no mundo. Petrópolis, RJ: Editora Vozes, 2014. p. 58.

${ }^{25}$ ORTELLADO, Pablo. Posfácio. In: SOLANO, Esther; MANSO, Bruno Paes; NOVAES, Willian. Mascarados: a verdadeira história dos adeptos da tática Black bloc. São Paulo: Geração Editorial, 2014. p. 286. 
os preços de alimentos, da gasolina, de aluguéis, da luz e diversos outros utensílios básicos denunciaram o descontrole da inflação e contribuíram para fortalecer a oposição ao governo. Nesse cenário, uma grande manifestação foi articulada no dia 15 de março de 2015, que conforme dados das polícias estaduais, reuniu cerca de 1,5 milhão de pessoas por todo o país. Tal manifestação reuniu predominantemente os setores da classe média nacional, que também tomaram as ruas na segunda fase das Jornadas de Junho.

O levante popular de junho de 2013 contribuiu para o surgimento de uma conjuntura favorável à eclosão de protestos que expressam demandas dos mais diversos segmentos da arena política nacional. Greves, principalmente do funcionalismo público, também cresceram e ganharam repercussão no país. Os setores progressistas continuaram engajados nas lutas sociais contra os cortes orçamentários na educação, os direitos dos trabalhadores, o acesso à moradia e a precariedade e o alto custo do transporte público. Os setores conservadores, por sua vez, também se mobilizaram trazendo pautas como o recrudescimento do combate a corrupção, o impeachment da presidente Dilma Rousseff, a ocorrência de uma intervenção militar, entre outras.

\section{CONSIDERAÇÕES FINAIS}

As Jornadas de Junho de 2013 encontram-se asseguradas pelo direito de manifestação previsto em nossa Constituição Federal e representam um avanço democrático à medida que trouxeram para a arena política nacional estratégias de luta até então abandonadas, devolvendo aos jovens a crença de que a participação direta pode ser um importante instrumento de transformação social.

Os manifestantes, ao ocuparem as ruas e praças de diversas cidades brasileiras, deram voz a seus descontentamentos, reivindicações e anseios em uma tentativa de romper com o "inferno urbano" então instaurado e reivindicar uma cidade não regida pela lógica neoliberal excludente. Ousaram sonhar com um direito ativo de construir uma cidade diferente, inclusiva, plural, que atenda de fato às necessidades coletivas.

Tendo em vista o período de instabilidade política e econômica vivenciado em nosso país, analisar o fenômeno das Jornadas de Junho de 2013 e as ramificações progressistas e conservadoras que originaram-se a 
partir de sua influência é de extrema importância para que ocorra a desconstrução do processo de criminalização das manifestações populares.

Tal processo é evidenciado por meio de inúmeras práticas dos poderes Executivo, Legislativo e Judiciário no sentido de cercear o direito de manifestação, pelas atuações policiais truculentas no trato para com manifestantes e pela mídia, que de modo tendencioso e simplista incute na população a ideia de que manifestantes são "inimigos" a serem combatidos pelo Estado.

Estudar o fenômeno das jornadas de junho de 2013 e a conjuntura de inferno urbano que as ensejaram é o primeiro passo no combate ao senso comum de que manifestantes são "vândalos" dispostos a colocar em cheque a ordem pública constituída. Eles são, na verdade, protagonistas de um período histórico de lutas contra os desajustes econômicos, políticos e culturais de nossa sociedade.

\section{REFERÊNCIAS BIBLIOGRÁFICAS}

ALVES, Giovanni. Precariado: a espinha dorsal dos protestos nas ruas das 353 cidades brasileiras. In: ALVES, Giovanni; ROCHA, Bruno Lima; GADEA, Carlos; COCCO, Giuseppe, VIANNA, Luiz Werneck; RICCI, Rudá. \#VEMpraRUA: outono brasileiro? Leituras. Caderno IHU Ideias, 2013, ano 11, nº191, p. 34-35. Disponível em: <http://www.ihu.unisinos.br/images/stories/cadernos/ideias/191xca dernosihuideias.pdf $>$. Acesso: 26 jun. 2015.

BECHARA, Ana Elisa Liberatore Silva. Liberdade de expressão e manifestações populares no âmbito democrático. Boletim IBCCrim. Ano 21, n. 249, agosto/2013.

BICALHO, Marcos Pimentel. O pesadelo da imobilidade urbana: até quando? Carta Maior, 4 jul. 2012. Disponível em: < http://cartamaior.com.br/?/Editoria/Politica/O-pesadelo-daimobilidade-urbana-ate-quando-\%0D\%0A/4/25527>. Acesso: 25 jun. 2015.

BRASIL. Constituição (1988). Constituição da República Federativa do Brasil. Brasília, DF: Senado, 1988. Disponível em: <http://www.planalto.gov.br/ccivil_03/constituicao/constituicaoco mpilado.htm>. Acesso: 26 jun. 2015. 
BRASILINO, Luís; GODOY, Renato; NAVARRO, Cristiano. O junho de 2013. Le monde diplomatique Brasil. 02 jul. 2013. Disponível em: <http://www.diplomatique.org.br/artigo.php?id=1447>. Acesso: 07 jan. 2015.

CARNEIRO, Henrique Soares. Rebeliões e ocupações de 2011. In: HARVEY, David et al. Tradução de João Alexandre Peschanski. Occupy: movimentos de protesto que tomaram as ruas. São Paulo: Boitempo Editorial: Carta Maior, 2012.

CASTELLS, Manuel. Redes de indignação e esperança: movimentos sociais na era da internet. Tradução de Carlos Alberto Medeiros. Rio de Janeiro: Jorge Zahar Editor, 2012.

CHAUÍ, Marilena. As manifestações de junho de 2013 na cidade de São Paulo. Teoria e Debate, 27 jun. 2013. Disponível em: <http://www.teoriaedebate.org.br/materias/nacional/manifestacoesde-junho-de-2013-na-cidade-de-sao-paulo>. Acesso: 26 jun. 2015.

DATAFOLHA. Cresce apoio a protestos contra a tarifa de ônibus entre paulistanos. São Paulo, 19 jun. de 2013. Disponível em: <http://datafolha.folha.uol.com.br/opiniaopublica/2013/06/129761

9-cresce-apoio-a-protestos-contra-a-tarifa-de-onibus-entrepaulistanos.shtml>. Acesso: 23. Ago 2014.

DELMANTO, Roberto. Os black blocs e a Lei de Segurança Nacional. Boletim IBCCrim. Ano 21, n. 253, dezembro/2013, p. 04.

ESTADÃO. MPL anuncia que não convocará mais protestos em SP. 21 jun. 2013. Disponível em: < http://www.estadao.com.br/noticias/geral,mpl-anuncia-que-naoconvocara-mais-protestos-em-sp, 1045263>. Acesso: 23 jun. 2015.

GOHN, Maria da Glória. Manifestações de junho de 2013 no Brasil e praças dos indignados no mundo. Petrópolis, RJ: Editora Vozes, 2014.

G1. Veja pesquisa completa do Ibope sobre os manifestantes. 24 jun. $2013 . \quad$ Disponível em: <http://g1.globo.com/brasil/noticia/2013/06/veja-integra-dapesquisa-do-ibope-sobre-os-manifestantes.html>. Acesso: 26 jun. 2015.

MAIOR, Jorge Luiz Souto. A vez do direito social e da descriminalização dos movimentos sociais. In: MARICATO, Hermínia et al. Cidades rebeldes: Passe Livre e as manifestações que tomaram as ruas do Brasil. São Paulo: Boitempo Editorial: Carta Maior, 2013. 
ORTELLADO, Pablo. Posfácio. In: SOLANO, Esther; MANSO, Bruno Paes; NOVAES, Willian. Mascarados: a verdadeira história dos adeptos da tática Black bloc. São Paulo: Geração Editorial, 2014.

PESCHANSKI, João Alexandre. Direita e esquerda no espectro do pacto do silêncio. Publicação oficial da Associação dos Juízes para a democracia. Ano 14, n. 60, agosto/2013.

PLANALTO NACIONAL. Pronunciamento da presidente da república, Dilma Rousseff, em cadeia nacional de rádio e TV. Secretaria de Comunicação Social da Presidência da República: Discursos. Brasília, de 21 de junho de 2013. Disponível em: < http://www2.planalto.gov.br/acompanhe-o-

planalto/discursos/discursos-da-presidenta/pronunciamento-dapresidenta-da-republica-dilma-rousseff-em-cadeia-nacional-deradio-e-tv>. Acesso: 20 fev. 2015.

PUJOL, Antoni Francesc Tulla i; ROCHA, Fernando Goulart; SAMPAIO, Fernando dos Santos. Manifestações populares no Brasil atual: sociedade civil em rede e reivindicações sobre o poder político. In: XIII COLOQUIO INTERNACIONAL DE GEOCRÍTICA: El control del espacio y los espacios del control. Barcelona, 05-10 mai, 2014, p. 9. Disponível em: < http://www.ub.edu/geocrit/coloquio2014/Antoni\%20Francesc $\% 20$ Tulla\%20i\%20Pujol.pdf>. Acesso: 20 jan. 2015.

RICCI, Rudá. A disputa política está nas ruas. In: ALVES, Giovanni; ROCHA, Bruno Lima; GADEA, Carlos; COCCO, Giuseppe, VIANNA, Luiz Werneck; RICCI, Rudá. \#VEMpraRUA: outono brasileiro? Leituras. Caderno IHU Ideias, 2013, ano 11, nº191, p. 28. Disponível em: <http://www.ihu.unisinos.br/images/stories/cadernos/ideias/191xca dernosihuideias.pdf $>$. Acesso: 26 jun. 2015.

SARLET, Ingo Wolfgang; MARINONI, Luiz Guilherme; MITIDIERO, Daniel. Curso de Direito Constituional. 3. ed. São Paulo: Editora Revista dos Tribunais Ltda, 2014. 